\title{
Gender, Vending and Livelihood Sustainability in Zimbabwean Urban Areas: A Case Study of Katanga 'Speed' Market in Norton
}

\author{
Gladys Balance \\ Midlands State University, Zimbabwe
}

\begin{abstract}
This study explored the link between gender, vending and livelihood sustainability in Zimbabwean urban areas. The focus was on female and male vendors at Katanga 'Speed' market in Norton. Participants were female and male vendors selling food items including meat, poultry and fish products. Purposive sampling was adopted for the study. Data on the experiences, views and perceptions on vending activities was generated through observation, photography and interviews. Data analysis was done through descriptive statistics and corresponding percentages. In addition, data from interviews was analyzed thematically using common themes that emerged from the interviews on the challenges faced by vendors. To analyze the sustainability of the vending activities from a health perspective, the study questioned the reasons why vendors were not relocating to an established vending site less than two kilometers from the 'Speed' market, choosing to remain where there are no toilets or water facilities. The research recommends council authorities to prioritize the relocation of vendors and the involvement of organizations on educating vendors on food handling and hygiene to safeguard the health of the people consuming food sold at Katanga
\end{abstract}

Keywords: Gender, vendors, informal sector, women, livelihood, fish, meat, urban areas.

DOI: $10.7176 / \mathrm{PPAR} / 9-3-16$

Publication date:March $31^{\text {st }} 2019$

\section{Introduction}

The majority of the urban dwellers in Zimbabwe's high-density suburbs have in recent years succumbed to the harshness of the economic challenges that has reduced the majority of the people to the poorest population of this country. Kamidzi (2009) points out that the situation of the urban poor has been a result of the catastrophic effects of the national economy, which has left many of its once-vibrant sectors and industries significantly depleted. In an effort to alleviate their poverty situation, the urbanites define their livelihoods strategies according to the available resources in their geo-location. It has become typical that people diversify portfolios of activities to sustain their livelihoods and deal with their poverty. In the midst of such diversification is vending, where women are mostly involved in the less profitable enterprise. For example, in Katanga, a location found within the town of Norton in Zimbabwe, livelihoods of the urban poor, particularly the women, are based on food vending including fish, meat as well as fruit and vegetable. The hive of activities is notable at the popularly known 'Speed' market area in Katanga township of Norton. The population density of the township as of 2012 census provided by the Zim-Stats was approximated to be at 67.591 .

\section{Background to the study}

A combination of economic recession, economic liberalization, structural adjustment programmes (SAPS), privatization and declining rates of state involvement have often left people in Sub Saharan Africa in a vulnerable situation in terms of living standards. Peterson (2008) points out that the informal sector has become a refuge for many in the face of such economic challenges. Empirical evidence on informal trading in the region's towns and cities demonstrates that both men and women are involved, differing only in the commodities that they trade in and the scale of their trading activities. According to the International Labour Organization (ILO) (2012) women represent a larger share of the formally unemployed and they often succumb to poverty which invariably affects their livelihoods leaving them with no option but to shoulder the burden of poverty. Vending in the street has therefore become a safe haven for most of the people affected. Tillerman (2012) and ILO (2012) support the above view by pointing out that in Sub Saharan Africa $85 \%$ of women participate in 'vulnerable' employment despite the fact that such employment activities are characterized by inadequate incomes, low productivity, and difficult conditions of work.

Arguments on the escalating number of men and women in street vending is also supported by Dabir- Akair (2004) who argues that, the mushrooming of street vendors has been a result of global economic crisis, followed by the neo- liberal economic policies adopted by various states and governments which left large numbers of people jobless. Global Statistics on street vending reveals that in Asia, Latin America and Africa, vending has become a major source of livelihood for the majority of the population. The ILO (2012) reveals that in Sub Saharan Africa $85 \%$ of the total population is engaged in informal economic activities.

According to Bhowick and Saha (2012), one typical form of the informal sector is street vending. The duo alludes to the fact that street vending has been in existence since ancient times and in all civilization eras from 
the ancient to the medieval. Research findings by Hart (2004) point out that street vending has become a renowned survival strategy for the poor in many communities where it helps the participants meet their daily basic needs. Further, Hart (2004) found out that there has been growing trends in particular food vending within the urban areas of most developing countries. It has, therefore, been the women who have located themselves strategically within the street vending domain given the easy of entry and the limited resources needed as startup capital. Those who have survived the harsh operating environment have done so through resilience and determination to succeed.

Bhowick and Saha (2012) argue that in the ancient and medieval times street vending was held with some degree of tolerance. Hence their flourishment, compared to how the contemporary modern time vendors are treated by local authorities. The duo points out that the vendors are pushed around as if they are thieves or parasites eating into the wealth of the city. Despite being targeted by the municipality authorities, street vendors have also been castigated by the urban middle class who often complain about how the vendors make the urban life a living hell as they block pavements, create traffic problem and engage in anti -social activities. Given such attitudes and perceptions about the street vendors in all urban areas those involved have to survive in hostile environments despite the fact that they are service providers as well.

The growth of the informal sector has given credence to the idea that there is a potential entrepreneur in every human being. Hence the participation of a multitude of women in the sector. In a research by ILO (2013) findings were that in Africa the majority of the street vendors were women. ILO (2013) points out that $88 \%$ in Ghana, 68\% in South Africa and 63\% in Kenya are female street vendors. Only 10\% were said to be found in countries which have cultural restrictions which deters women from participating in the public sphere. Mate (2010:21) points out that "women's informal sector activities are typically at the lowest end of the sector, where earnings are not favorable". From Mate's assessment, men in the informal sector dominate the high return sectors such as the transport sector where they mostly operate their own vehicles.

Roever (2014) in a research on the informal sector and informal employment in developing countries revealed that a high share of women than men sell perishable goods which are more likely than other goods to spoil or to be confiscated during street raids. Empirical evidence on the informal sector demonstrates that both men and women participate in the sector, although statistics shows that the percentages of female vendors are higher than those of the males. The view is again supported by Kinyanjui (2014) who points out that, street vending is dominated by women and attributes the reason to the limited economic opportunities for women in both the rural and urban areas. Kinyanjui (2014) points to the women's need to augment the husband's income which results in the majority of the women engaging in street vending. Street vending is also deemed to have a special appeal to women due to its flexibility where vending can be easily done in conjunction with other gendered roles and other household chores. In Kenya, research findings by Kinyanjui (2014) were that vending by women was a way out of predicaments. Women vend when husbands cannot sustain the family or in some cases they carry out vending to supplement the husband's income.

\section{Research methods}

The research design consisted of mixed method. The study sought to explore the extent to which vending was a solution to women's poverty in Norton. As a result, a modesty sample size was selected to get a deeper understanding from the standpoint of the female vendors and other stakeholders linked to the market. The researcher felt the need to get varying and more reliable data that can depict what obtains in other high-density suburbs of Zimbabwe as ways of alleviating poverty. A pilot study of five questionnaires was administered at Katanga's fish vending site and the outcome was not encouraging given the fact that women at the site were not eager to complete the questionnaire. The researcher found out that the negativity to completing questionnaires was embedded in the politicized perceptions on researchers in the area and a general detest by vendors in interacting with researchers. Another realization was the level of illiteracy amongst the women at the vending site that led to a lack of interest in participating in the research. Given the above challenges the researcher then elected structured interviews as alternatives for data collection, a decision that was successful as selected persons could participate discretely. A photographic strategy was also selected to depict the various commodities and products sold at the open Speedy market. It was anticipated that the pictures would make an impact in displaying the value of sustainability in the development agenda particularly in poverty alleviation.

The targeted population was the female vendors situated at Katanga 'Speedy' market. Twenty female vendors were purposefully selected and successfully interviewed given the types of commodities they were vending in. For instance, the female vendors comprised of fifteen fish vendors, and five chicken and beef vendors. Seven male vendors were selected from amongst those who sold fish and were interviewed on their views and perceptions on vending activities and their business relations with female venders. The research also sought the participation of two Norton council authorities and two health personnel who participated on condition of anonymity.

The second phase of the research was done after a three-day general observation of the vendors' routine at 
the vending site. Although there are many females in the trade the researcher observed that there were regular and irregular vendors at the market. This observation was also supported by findings from the interviews when vendors were asked about their frequency at the market. As a result, a balance had to be struck in interviewing the regular vendors and those whose vending activities were not so consistent. It was important in this research to determine the factors that contributed towards regularity and irregularities in the vending business. The criteria for an in-depth analysis on the impact of street vending as a strategy for poverty alleviation, individual female vendors were identified due to their frequency at the market. The purpose for in-depth interviews was to gain detail on the lived experiences from the female vendors' perspective.

Direct observations were used on the fish, meat and vegetable vendors. The observation technique was used to examine how vendors managed their fish, meat and vegetable stalls and also how the vendors interacted with their customers and prospective customers. The observations were used in conjunction with photography, where the researcher captured various activities at the site for further analysis and triangulation with other collected data.

The female vendors were classified into three distinct categories, based on the type of merchandise they sold, for instance meat vendors, fish and fruit and vegetable vendors. Point to note was that most of the fish vendors were observed and interviewed at sun set through to the early hours of the evening given that, these women comprised of the groups that were involved in nocturnal vending which was determined by the supply of the fish products which were often brought to the market towards sunset.

\section{Review of related literature}

Researching on street vending in Bangkok (Thailand), Indra (2014) pointed to the significance of street vending as an important source of income for the poor. Indra (2014) explained that street vending in Bangkok is arguably a result of the Asian economic crisis of 1998 which is said to have affected the Asian group of countries known as the Asian Tigers. Groups of people who lost jobs as a result, found economic sanctuary in street vending. A clear and detailed profiling of street vending in Bangkok is given by Indra. However, a visible research gap from Indra's (2014) research is the dearth of information on the gendered nature of the street vending and the challenges that women as a specific group face.

FAO (2001) cited in Indra (2014) explains the issue of food vending in South-East Asia. It was found in this particular research that 1000 people were street vendors. Note that even in this case vendors were not categorised by their gender. Instead they were all looked at as a single entity, yet the vending dynamics affect males and females differently. Therefore, the current study takes the gap into cognizance and thus endeavours to show the different lived experiences of the male and female vendors. Research also falls short of bringing out the gendered nature of a vending trade and the differentiated challenges faced by both men and women.

A research by the Zimbabwean Standard News Paper (2015) on street vending in Zimbabwe's urban areas such as Harare, Mutare, Marondera and many others, shows the extent to which vending has become the largest source of informal employment for the majority of the urban dwellers particularly women who have no access to the formal sector. Changa (2013), Njaya (2014), Rau (2015), confirm in their research on street vendors in Zimbabwe the increase in the number of street vendors and existence of a hive of activities of street vendors. The researchers have attributed this to the consequence of the economic structural adjustment programme (ESAP). In support of the above view, New Zimbabwe (2017) cites the Zimbabwean Informal Sector Organization (ZISO) and the National Vendors Union of Zimbabwe (NAVUZ) who estimate that more than a million people are surviving on vending in Zimbabwe. What is important to note on these studies is the tendency to generalize. For example simply stating that $88,3 \%$ people are vendors without categorizing them according to gender. Just like in other countries cited above from South East Asia and West Africa, there is a dearth of information pertaining to the genderedness of those involved in the vending activities.

\section{Women and vending products}

Benie and Merten (2008) found out that women in the fish industry are basically responsible for post- harvest activities which involved fish selling. On the other hand research findings by the World Bank (2011) were that in most Asian countries fish selling is almost exclusively a domain for women, where 70-78\% of women are artisanal fish traders who deal in small fish quantities.

Shauddiwat (2013) found that female traders in Mumbai have been in the trade for close to thirty years. Knowledge and skills have been learnt from generation to generation. Another finding was that fish trading was the only source of livelihood as the participants pointed out their failure to pursue formal education. This study reveals that fish vending on the streets was due to the destruction of the Mahim Station Market by the administration to give way to the construction of the Pickle hospital. This supports the view that municipalities have a role to play in the displacement of vendors culminating in them vending in undesignated areas.

Hoffman and Bernahad (2007) reveal that meat vending in Burkinafaso emerged and became a source of livelihood for women. Similarly there has been an upsurge in the number of vendors taking up meat vending as 
an activity amongst food vendors in Zimbabwe's urban areas.

\section{Research findings and discussion}

\subsection{Demographic representation of female and male vendors at Katanga}

Eighty one percent of the vendors were female vendors confirming findings by Kamete (2009) that women dominate the informal vending sector in Zimbabwe. The study thus found that female vendors at Katanga are particularly vibrant in petty commodity trading which amongst the lists of items of trade are perishable food products.

\subsection{Vending products at Katanga.}

The study observed a high degree of product diversification amongst the vendors at Katanga.

Table 1: Product diversification

\begin{tabular}{|l|l|l|l|}
\hline Products sold & Female & Male & $\%$ \\
\hline Fish & 17 & 5 & 61,1 \\
\hline Poultry & 4 & 0 & 11.1 \\
\hline Meat & 5 & 1 & 16.6 \\
\hline Fruits and vegetables & 2 & 2 & 11.1 \\
\hline \multicolumn{1}{|c|}{ Totals } & 28 & 8 & $99.9 \%$ \\
\hline
\end{tabular}

The vending activities at Katanga are largely based on food vending ranging from fresh fish and meat products to processed fish as well as fruit and vegetable vending. Contrary to the view that street vending is largely a domain for un-married women from single headed households, this study found out that the $74.4 \%$ of the interviewed females were in actual fact married while $25,6 \%$ vendors were from single headed households.

The photographic data gathered by the research shows the categories of products sold at the Speedy market ranging from fish, beef products and poultry products. The majority of the vendors at Katanga revealed that they preferred selling fish compared to other products. Seventy-five percent of the interviewed respondents attributed their choice to resources availability and accessibility. The vendors argued that buying fish from the local middle men was ideal given the constraints posed by the females triple roles that they have to satisfy besides participating on the fish market.

In-depth interviews with female fish vendors provided data on the extent to which the income the vendors accumulated varied from day to day. The research found out that competition for customers was rife given the rate at which new vendors join the market every day. Respondents pointed out that selling at Katanga was now based on how lucky one was and some blamed fellow vendors for unethical means of luring customers.

The vendors also lamented the unsustainable nature of the vending activities which they characterized as a hand to mouth economic activity. It is from this finding that the study concluded that in as much as the vendors' practical needs are met they however are not in a position to accumulate adequate incomes that can allow them to engage in bigger projects and as such they continue to revolve at the lowest level of the vending strata. Vendors were also disheartened by the lack of guarantee on the availability of the fish, given that harvesting substantial amounts of fish is seasonal. The Pictures below reveal that fish vending is a predominant activity at the market. There are differences in the types of fish sold as shown below, fresh and processed fish.

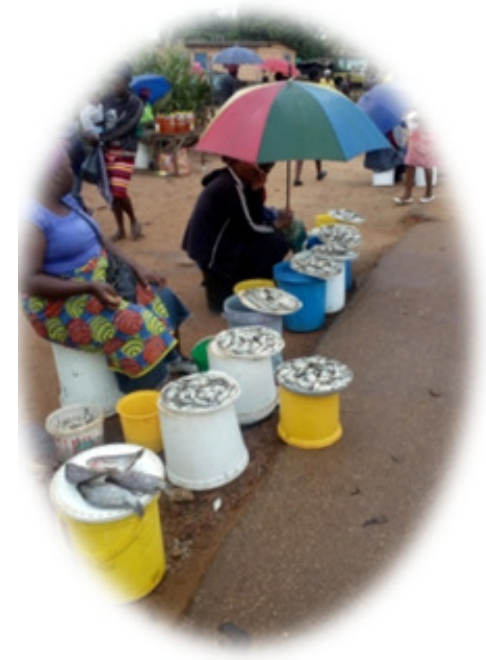

Fig. 1: Women selling fresh fish

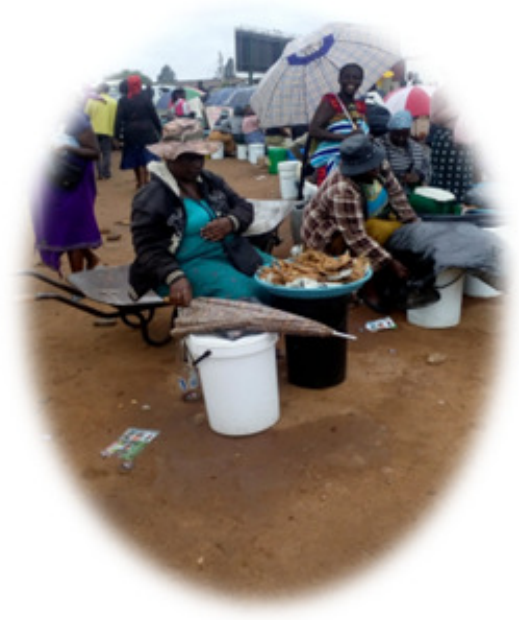

Fig. 2: Women selling dried fish

The alternative of roasting fish was attributed to challenges caused by the unreliable electricity supply in the 
township which made it difficult for the traders to refrigerate fish and other products. The vendors said they could not afford storage facilities given that some nearby residents were providing overnight refrigeration at a cost of $\$ 2.00$. Ninety-five percent of the interviewed female vendors pointed out that they could not afford to pay what they considered to be exorbitant charges for an overnight facility.

A different group of respondent constituted $11,5 \%$ of the vending sample revealed the need to avoid stiff competition that characterized the selling of fish. These respondents argue that selling beef products such as ox lungs and beef sausages was a better option and more profitable. An inquiry into the source of these products did not yield any positive results from the vendors who seemed bent on not divulging their sources for fear of competition. The study therefore came to a conclusion that sources of these meat products were most likely unsuitable sources for food products.

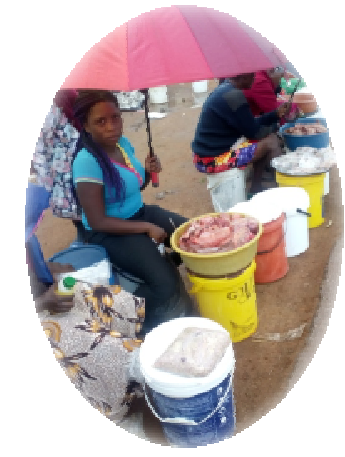

Fig 3: Ox lungs

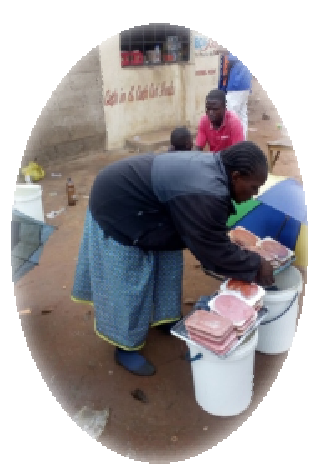

Fig 4: Beef sausages

The pictures above show female vendors selling beef sausages and ox lungs at Katanga. The researcher noticed that these vendors were going an extra mile in the way they presented their products for sell. The art of packaging has for this particular vendor yielded profits for her and resulted in her success in retaining her customer base for over three years at the market.

The study also interviewed vendors who sold poultry products such as chicken feet, chicken intestines, chicken skins and chicken heads. The findings were that $15,4 \%$ of the respondents acknowledged satisfaction with the profit margins they were realizing from selling chicken products. The respondents revealed that their success in the business was due to the limited competition, which was attributed to challenges in sourcing these products. It was pointed out that a kilogram of chicken intestines costs 75 cents at wholesale price. At retail price a cup of the intestines is sold at 50 cents. Thus, vendors could realize at most $\$ 2,00$ from the kilogram sold making a profit margin of $\$ 1,25$ per kilogram.

Figure $9 \mathrm{a}$ and figure $9 \mathrm{~b}$ below show a female vendor who has sought to diversify her products by selling both intestines and cutlets of chicken to capitalize on her profit margins. Figure 9a shows a process of weighing a cup of 50 cents worth of intestines while figure $9 \mathrm{~b}$ shows further processing of chicken pieces into smaller profitable cutlets.

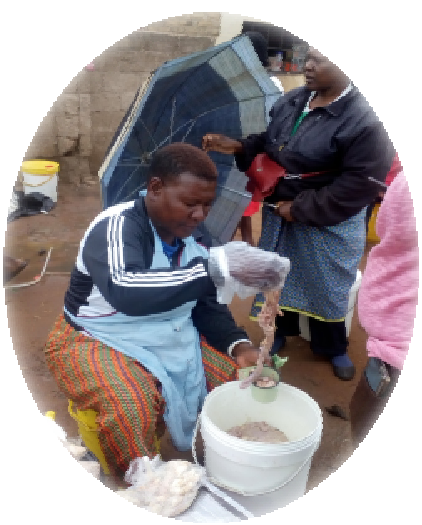

Fig. 5: Chicken intestines

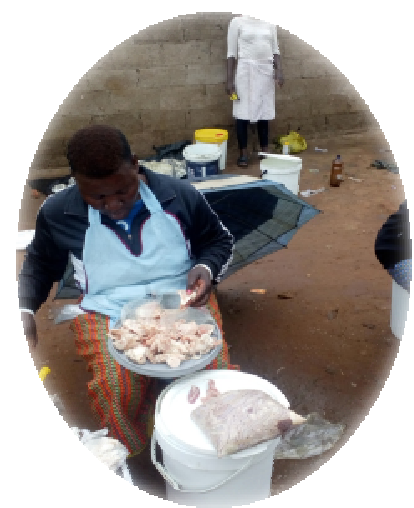

Fig. 6: Chicken cutlets

6.3 Challenges faced by vendors at Katanga.

The vendors at Katanga vending site identified a number of challenges. Topping the list was the issue of 
harassment by the council authorities. Consistent with the findings by Yasmeen (2014) on street vending and police harassment, the study found out that venders at Katanga were not an exception and as such, their daily vending activities were filled with uncertainties. It has been the norm that Norton town municipality police subject these people to raids and often confiscate their goods whenever they failed to hide them from the police. In most cases, those who were arrested were often forced to pay heavy fines and their goods never returned to them. Such treatment by the municipality police was deemed unfair by the venders as they were made to suffer what they called 'double losses'. The cat and mouse game by the vendors and the police was observed by the researcher to be a real threat to food safety and consumer health.

The participants identified corruption by the municipality police as a major drawback as efforts to avoid arrests and fines forced them to pay bribes which according to them was day light robbery. The vendors revealed that such practices were detrimental to the sustainability of their economic activity given the little profit margins they made from selling fish, meat and vegetables at Katanga. Bhowick and Saha (2012) earlier alluded to the concept of 'greasing the palms' of authorities, a situation which the vendors at Katanga pointed out to be detrimental to their efforts of earning a livelihood through vending.

\subsection{The politics of male involvement in vending at Katanga}

The politics of male involvement at the vending site was also identified as another challenge faced by women. A research by Balance (2017), on women in the informal sector revealed that women fail to thrive sustainably in the informal sector because of the inferior goods they trade in. Typical observation during the study was the unmatched competition between women and men who had infiltrated the vending site. A typical picture of male versus female vendor competition was witnessed on the arrival of a small Honda Fit vehicle selling fish in bulk. The most amazing observation was the speed with which the buckets were sold out. Below is a typical boot selling fish episode at Katanga where one female vendor sold fish straight from the ground while a male vendor sold from his car and had customers scrambling for the fish.

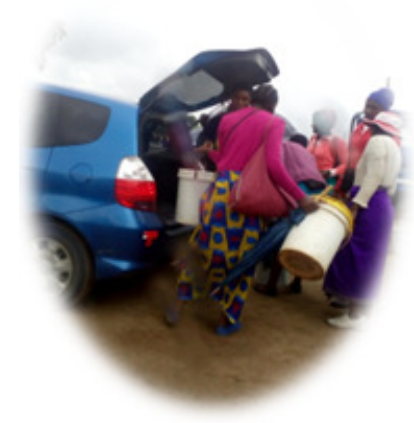

Fig. 7: Typical male vending

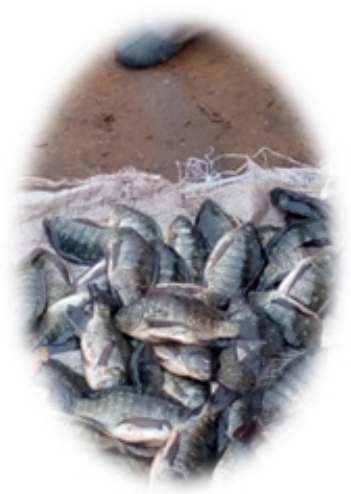

Fig. 8: Typical female vending

Thirty percent of the women interrogated revealed that they preferred buying from boot sellers as their products were more hygienic compared to the fish sold by women spread on buckets and the ground. Coupled with perceived environmental hazards female vendors faced, they also revealed that male vendors used unethical means to steal customers from them. One hundred percent of the female respondents expressed sadness on how male competitors talked ill about their products to potential customers. Given such challenges $23 \%$ of the interviewed female vendors revealed that the situation made it difficult for them to maintain adequate capital to reinvest into the vending projects.

\subsection{Questioning the suitability of 'Speed' open space as a vending site.}

The study questioned the suitability of the area as a site for continued selling of food products without compromising the well-being of both the vendors and the consumers of the products sold. The observation made by the researcher was that at Katanga it was business as usual despite the huge amounts of rotting garbage, stagnant dirty water in the vicinity of the vending fish buckets and spread fruits and vegetables. Both the vendors and customers appeared to turn a blind eye to the potential health hazard that was looming around them. The research also observed that despite the delicate nature of the products sold the market area does not have any running water facilities. Vendors relied on water stored in small water bottles ranging from $500 \mathrm{ml}$ to 2 litre bottles.

The deplorable environmental conditions at the vending site were captured in the following pictures. 


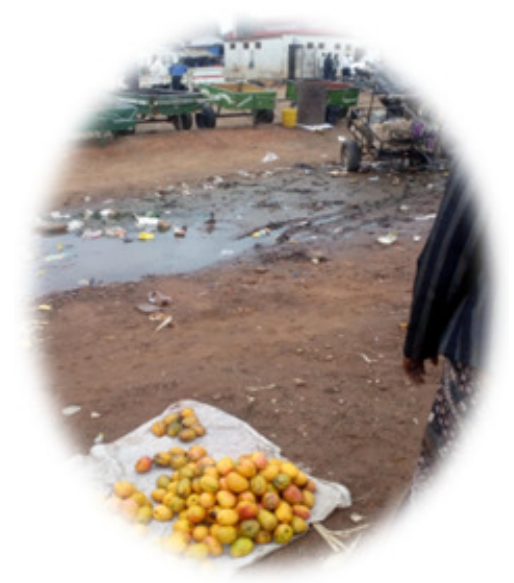

Fig. 9: Vending site

\subsection{The New vending site}

The study established that the local authority has made an effort through the Constituency Development Fund to construct a site for the fish vendors but the occupation of the facility has turned out to be controversial. Research by Wang and Kin (2016) on the critical roles of street vendor organization in relocating street vendors into public markets in Taiwan revealed the existence of conflict and negotiations between vendors and the local authorities. The conclusions drawn by the above duo on the situation of vendors and local authority relationships are synonymous with this study's findings. In the case of relocating vendors from the Katanga open space market, the study found that there has been efforts made by the Norton council under the Constituency Development Fund to construct centralized vending stalls with complete toilet and water facilities as shown by the photograph in Fig 10.

The vending stalls were built in 2009 by the Norton Community Development fund (CDF) to house the fish vending community in what was believed to be a standard and hygienic environment. Ninety percent of the interviewed fish vendors were offered vending space at the new site. Nonetheless, all of them refused to move to the new site arguing that relocating to the new site was not in their best interest. A study by Lyons and Msoka (2010) revealed that new locations often resulted in vendors losing their customer base. This view is typical with findings in this study about fears to be relocated to the new sites by both the fish vendors and meat vendors. Respondents pointed out that moving to the new site could result in them losing customers from nearby residential locations. This observation is in sync with observations by Kim (2015) who observed that, once vendors are left at unauthorized sites for too long, they develop a sense of entitlement to the space and the need to maintain the status quo resulting in difficulties when time comes for them to be moved. Resistance to move to the new site is evidenced by the extent to which the structure has become a huge white elephant, which is slowly becoming dilapidated.
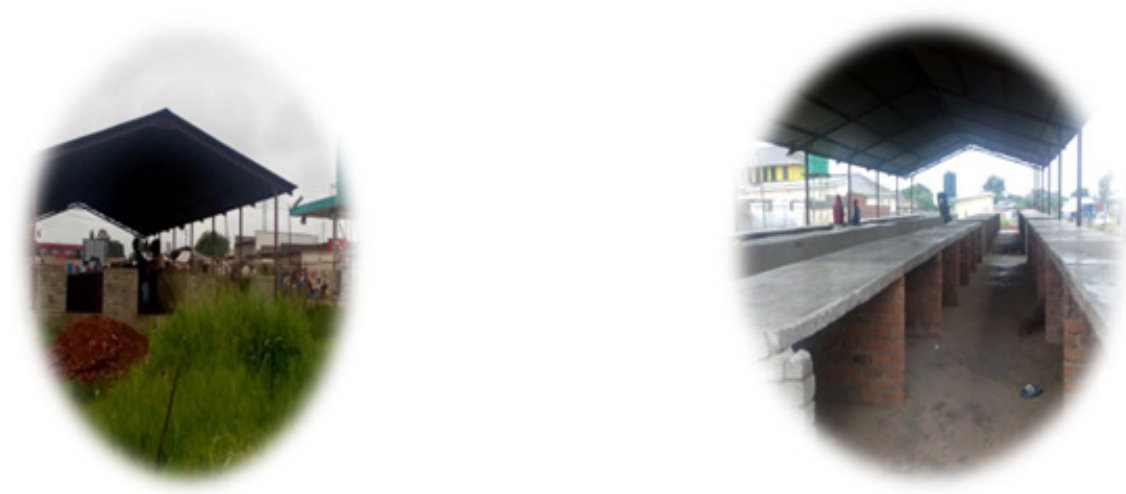

Figure 10: New unused Fish Vending Stall at Katanga

Besides resisting the site as an off the street market, the study learnt that the relocation has been largely compromised by the extent to which its construction has been politicized. Speaking anonymously, one respondent pointed out that the sustainability of the vending activities at Katanga were largely hampered by the fact that the people allocated the vending stalls were afraid of occupying the space whose construction was spear 
headed by council members from a political opposition party. Yet the majority of the vendors were presumed to be supporters of the ruling party. Premised on this view the study concludes that the vendor development agenda and the sustainability of such are being and will continue to be compromised as long as politics take precedence over the growth and wellbeing of vendors.

\section{Conclusion and recommendation}

This study discussed the gender characteristics of vending at Katanga 'Speed' market. The study established that male vendors had more resources for business than female vendors did. The study questioned the reasons why vendors were not relocating to an established vending site less than two kilometers from the 'Speed' market, choosing to remain where there are no toilets or water facilities. The research recommends council authorities to prioritize the relocation of vendors and the involvement of organizations on educating vendors on food handling and hygiene to safeguard the health of the people consuming food sold at Katanga

\section{References}

FAO (2001) Promises and challenges of the informal food sector in developing countries :In collaboration with the Agricultural Economics and Engineering Department (University of Bologna, Italy) and the Department of Sociology and Anthropology (University of Ottawa, Canada).

Hart, K. (2004). 'The Political Economy of Food in An Unequal World', in Lien, M and Nerlich, B. (eds) Politics of Food. Oxford: Berg

Hoffman, Irene, and Bernhard, Judith (2007). "Meat Marketing in Burkina Faso After the Devaluation of the FCFA: Insights into the Functioning of Informal Market Systems." Food Policy 32:229-45.

Indrasari, T, I Rothenberg, A. D. Gaduh, A, Burger, N. E., Chazali, C, \& Radikun, Rini,S, C and Weilant, S, (2016). "Rethinking Indonesia's Informal Sector," World Development, Elsevier, vol. 80(C), pages 96-113.

Kamete, A. Y (2009), "In the Service of Tyranny: Debating the Role of Planning in Zimbabwe's Urban 'Cleanup' Operation", Urban Studies Vol 46, No 4, pages 897-922

Kinyanjui, M. N (2014) Women and the Informal Economy in Urban Africa: From the Margins to the Centre. Zed Books Ltd, London.

Masonganye, M. (2010). Street trading in Tshwane Metropolitan Municipality: Realities and challenges. UrbanLandmark.Retrievedfromhttp://www.urbanlandmark.org.za/downloads/report_street_trading_jan2010 .pdf, date 06.26.2015.

Ongori, H. and Migiro, S. (2010). Role of information communication technologies adoption inSMEs: Evidence from Botswana. Research journal of information technology, 1 (2): 79-85.

Roever, S (2014) Informal Economy Monitoring Study Sector Report: Street Vendors. IEMS Informal Economy. Weigo

Shaudaiwat, P (2013) Mumbai District Women Fish Vending Cooperative in India.icsf@icsf.net program associate, ICSF

Tillerman, E (2012) Women Vendors in Dar es Salaam: Surviving or Climbing the survival ladder. Exploring the livelihoods of women in the urban food, beverage vending sector in Tanzania. Lund University.

Dube, D and Chirisa, J (2012) The informal city. Assessing its scope, variants and direction in Harare. University of Zimbabwe. Harare

Michèle (2010) Commodities and Competition: The Economic Marginalization of Female Food Vendors in Northern Mozambique. Women's Studies Quarterly, Vol. 38, No. 3/4, MARKET (FALL/WINTER 2010), pp. 163-181 Published by: The Feminist Press at the City University of New York

Lyons, M and Snoxell, S. (2005). "Creating Urban Social Capital: Some Evidence from Informal Traders in Nairobi." "Sustainable Urban Livelihoods and Marketplace Social Capital: Urban Studies 42(7): 1077-97 